\title{
LIMA EN 1613. ASPECTOS URBANOS
}

Para la realización de este trabajo nos basaremos fundamentalmente en el Padrón de Indios de Lima dt: 1613, realizado por Miguel de Contreras, notario público, a instancias del virrey don Juan de Mendoza y Luna, marqués de Montesclaros. Este dispuso elaborar un censo de Lima, pero desgraciadamente sólo se ha conservado la parte correspondiente a ia población indígena.

Contreras y sus ayudantes recorren la Ciudaci cie los Rey'es y anotan de cada uno edad, lugar cie nacimicnto, caso de no haber nacido en Lima los años que llevan residiendo en clla, nombre de cacique y encomendero, estado civil, número de hijos y sus edades, profesión. Junto a estos datos en algunos casos aparecen otros adicionales, como son dónde se encuentra su lugar de trabajo, para quién trabajan, noticias sobre la vivienda (si es propia, alquilada, es un corral...), bienes que poseen. No faltan tampoco peculiaridades de la persona: es cojo, tartamudo, tiene el «rostro herraclo».

Se incluyen en el padrón indios de procedencia asiática; son los denominados «indios de China, Japón y la India de Portugal», los cuales aparecen consignados aparte, al final del documento.

Hay que señalar que mientras que los indio: americanos están inscritos por calles, los asiáticos figuran uno tras otro. Las distintas calles de la ciudad se señalan con un número $\mathrm{y}$, en algunos casos, junto a éste, aparece la denominación de la misma. Es curioso que en muchos casos las vías no debían tener nombre y se las designa por el del vecino principal que vivía en ella: «Cuadra donde vive D. José de Ribera». En otras ocasiones se las nomina por su situación («Cuadra de la 
Merced a la calle de los Mercaderes»). Aunque también las había con su nombre, como la mencionada de los Mercaderes, la de las Mantas, etc.

Un número amplio de páginas lo ocupan los indios que residían en conventos y edificios religiosos pero, curiosamente, sólo los varones. Las mujeres, que seguro residían en los monasterios femeninos, no se mencionan.

Llama la atención que no se incluyan en el padrón los indios de Santiago del Cercado, a pesar de su proximidad a Lima, ni tampoco los de la reducción franciscana de Magdale$n a, u$ otros enclaves vecinos a la ciudad, dándose la circunstancia de que en muchos casos trabajan en Lima personas que residen en estos lugares o incluso en El Callao.

Al leer detenidamente el padrón hemos observado algunas anomalías como, por ejemplo, personas que aparecen dos veces inscritas. Asimismo, es posible que los datos no sean demasiado exactos, pues a veces desconocen, o dicen desconocer su edad, en cuyo caso el escribiente coloca la que a él le parece; o bien ignoran su lugar de origen, los años que llevan residiendo en Lima, quién es su encomendero o cacique. También figuran muchos como «ausentes». Quizás esta falta de «precisión» se puede deber a que, si el padrón se hizo con fines fiscales, se pretendiese eludir datos e información para huir del pago de tributos.

A pesar de que el padrón se refiere a población india, aporta noticias sobre las distintas etnias que convivían en la ciudad. Por ejemplo, aparecen españoles mencionados como dueños de talleres, de viviendas, encomenderos, etc. Igualmente se citan mulatos, mestizos y negros. Por todo ello se trata de un documento extraordinariamente importante, sobre el que ya se han hecho algunos estudios.

De ellos es de destacar la reconstrucción de la ciudad basándose en el padrón, realizada por Juan Bromley, así como el capítulo «Lima en 1613», ambos en el libro Evolución urbana de la ciudad de Lima, del que es coautor José Bar- 
bagelata '. En el trabajo se mencionan las distintas calles, aportando datos sobre los vecinos más ilustres que en ellas residían, edificios destacados...

Asimismo, cabe mencionar la publicación que hizo del padrón Noble David Cook, en la que se incluye un estudio preliminar del mismo ${ }^{2}$.

Paul J. Charney es también autor de una investigación inspirada en este documento, en el que inserta, sobre el plano reconstruido por Bromley, unos signos indicativos del número de indios que residían en las distintas calles de la ciudad ${ }^{3}$.

Recientemente Javier Flores, en su artículo Hecbicería $e$ idolatría en Lima colonial (Siglo XVII), inserta comentarios sobre algunos aspectos de este censo ${ }^{4}$.

En este trabajo nuestra idea es tratar temas relacionados con el urbanismo, concretamente dos: la vivienda, qué puede cleducirse acerca de la casa urbana limeña en estcs inicios del siglo XVII, y la disposición de las personas en función de su profesión dentro de la trama ciudadana.

Hemos seguido la publicación de N. D. Cook, basada en el manuscrito que se conserva en la Biblioteca Nacional de Madrid. Advertimos que la numeración de calles del mismo no coincide con la dada por Bromley en su reconstrucción.

\section{LIMA EN 1613}

Lima se fundó el 18 de enero de 1535 con el nombre de Ciudad de los Reyes. El plano, una cuadrícula hipodámica o damero, se llevaba ya hecho sobre un papel y, según Bernabé Cobo, tenía las medidas de las calles y manzanas, colo-

\footnotetext{
1 Bromlcy, Juan y Barbagelata, José: Evolución urbana de la ciudad de Lima. Lima, 1945.

2 Padrón de indios de Lima en 1613. Introducción de Noble David Cook. Lima, 1968.

3 Charncy, Paul J.: El indio urbano: un análisis económico y social de la población india en Lima en 1613. «Histórica», vol. XII, núm. 1. Lima, julio 1988, págs. 5-33.

4 Flores Espinoza, Javier: Hechicería e idolatría en Lima colonial. (Siglo XVII.) En Poder $y$ violencia en los Andes. Cuzco, 1991.
} 
cándose en la parte correspondiente a cada solar ei nombre del vecino al que se concedía".

La población estaba constituida por 117 manzanas dispuestas formando un rectángulo (nueve por trece). Cada cuadra tenía 450 pies de lado y constaba de cuatro solares. Las calles eran de cuarenta pies de ancho cada una ".

La plaza mayor se hizo suprimiendo una menzana, como cra habitual en la época; aunque en este caso no estaba ubicada en el centro del plano, sino que se desplazó hacia el Norte, hacia el río, pues la ciudad estaba a orillas del Rímac.

En 1613, según la reconstrucción de Juan Bromley, la población ha crecido y la regularidad del plano inicial se ha visto alterada en algunas zonas. La parte que se mantiene en líneas generales más fiel a la traza primitiva es la parte oeste. El extremo sur ha sufrido notables alteraciones: las manzanas han perdido en algunos casos su forma cuadrada, e incluso las calles no son perpendiculares unas a otras, sino que sufren inclinaciones.

No obstante, la parte más caótica y menc)" respetuosa con el trazado inicial es la zona oriental. Aquí encontramos manzanas y plazas irregulares, como las de Sarita Ana y el Santo Oficio. Es la zona donde se concentran buen número de conventos y monasterios y, como es sabido, en esta época nos encontramos con la «ciudad conventual». Mediante donaciones y compras se van incluyendo dentro del recinto casas e incluso calles colindantes, que iban «transformando» la red urbana. Es asimismo la zona donde se sitúan edificios educativos: Universidad, colegios... A través de calles irregulares la ciudad se prolonga hasta el Cercado. Era éste una reducción creada para acoger a indios de encomiendas vecinas; su forma era un rectángulo con unas manzanas cuadradas, 35 en total, y una curiosa plaza romboidal en el centro. Estaba rodeado de un alto muro, de ahí el nombre de Cercado, aunque su denominación primera era Santiago, y en él se abrían dos puertas;

5 Cobo, Bernabé: Historia de la fundación de Lima. Lima, 1882, pág. 23.

6 Ibidem, pág. 43. 
una principal en el extremo sur-oeste, donde terminaba la calle del Cercado ( $n .^{\circ} 1$ a 3 ), y otra trasera en la esquina Noroeste, en la que también finalizaba una vía ( ${ }^{\circ}{ }^{\circ}$ (6), que debía estar muy poco habitada en esta época.

La parte norte de la ciudad era la que lindaba con el río. En principio la idea fue dejar allí una zona sin construir para ejido, pero pronto se empezaron a edificar en ella unas manzanas irregulares, que en muchos casos resultaron peligrosas, pues las avenidas del Rímac a veces ocasionaban derrumbamientos y desgracias, como en la llamada Barranca de San Francisco; se trataba de la parte trasera del convento, por donde era peligroso el paso, especialmente en períodos de crecidas, aunque esta circunstancia no impidió que allí residieran numerosas personas.

Al otro lado del río surge un barrio, San Lázaro. Pronto se pobló, pues empezaron a surgir casas a un lado y otro del camino a Trujillo que lo atravesaba. Allí instaló Antón Sánchez una leprosería o lazareto que dio nombre a la zona. Fue en principio, un lugar poblado por indios que luego se trasiadaron al Cercado al fundarse éste en tiempos del virrey don Francisco de Toledo, pasando los terrenos al Cabildo, si bien en 1613 es numerosa la población indígena que sigue residiendo allí.

San Lázaro se comunicaba con la ciudad a través del puente que, en 1613, estaba lecién inaugurado. Su trazado seguía un poco «por libre» la cuadrícula. En un extremo del barrio se hallaba la Alameda de los Descalzos, también acabada de estrenar, pues se había finalizado en 1611. En él se encontraban además el rastro, las carnicerías, ter.erías, el quemadero y otra serie de instalaciones contaminantes o peligrosas, como una fábrica de pólvora. Pero era también una zona de expansión y recreo, pues, además de la mencionada Alamecla, lugar de paseo habitual, existían numerosas pulperías y tambos, que daban al lugar un carácter lúdico.

El verdadero centro neurálgico de la población era la Plaza Mayor. En ella se situaban una serie de edificios decisi- 
vos en la vida ciudadana. El lado norte lo ocupaban las Casas Reales. Su frente estaba plagado de «cajones» o tiendas portátiles, que solían ser propiedad del Cabildo de la ciudad. Estos enmascaraban parte de la fachada, ya que sólo dejaban visible el piso superior y la puerta de acceso.

El lado este lo ocupaban las casas del arzobispo y la catedral, ante la cual se encontraba un cementerio El Sur era el llamado Portal de Botoneros; en él existían múltiples tiendas de sederos y botoneros que daban nombre al lugar.

El oeste, con portales a todo lo largo, lo ocupaban casas particulares, ante las cuales se situaban el llamado Portal de Escribanos, y las Casas de Cabildo.

En el centro de la plaza se situaban cajones y tenderetes, asimismo existía una fuente inaugurada en $1578^{\circ}$, que años después sería sustituida por la actual, de la que es autor Pedro de Noguera.

Otra plaza no muy lejana de la principal era la del Santo Oficio, actual Plaza Bolívar. Su forma era trapezoidal y en torno a ella se encontraban el edificio de la Inquisición, el hospital de San Cosme y Damián, más conocido como la Caridad, y la universidad de San Marcos. En el centro existía una pila de agua.

Más hacia el oeste se encontraba la plaza de Santa Ana, pues en ella estaba el hospital de este nombre; su forma era un trapecio irregular. En ella existían vendedcres al igual que en la plaza principal. Diseminadas por toda la población había plazuelas surgidas como atrios de los edificics religiosos, como las de San Francisco o Santo Domingo.

\section{LA VIVIENDA EN LIMA}

En la disposición primitiva de la ciudad cada manzana se debía dividir en cuatro solares, entregándose cada uno a una familia. Sin embargo, esta idea original, a medida que la ciu-

7 Libros de Cabildos de Lima. Tomo VIII. Lima, 1935-1965, pág. 69). 


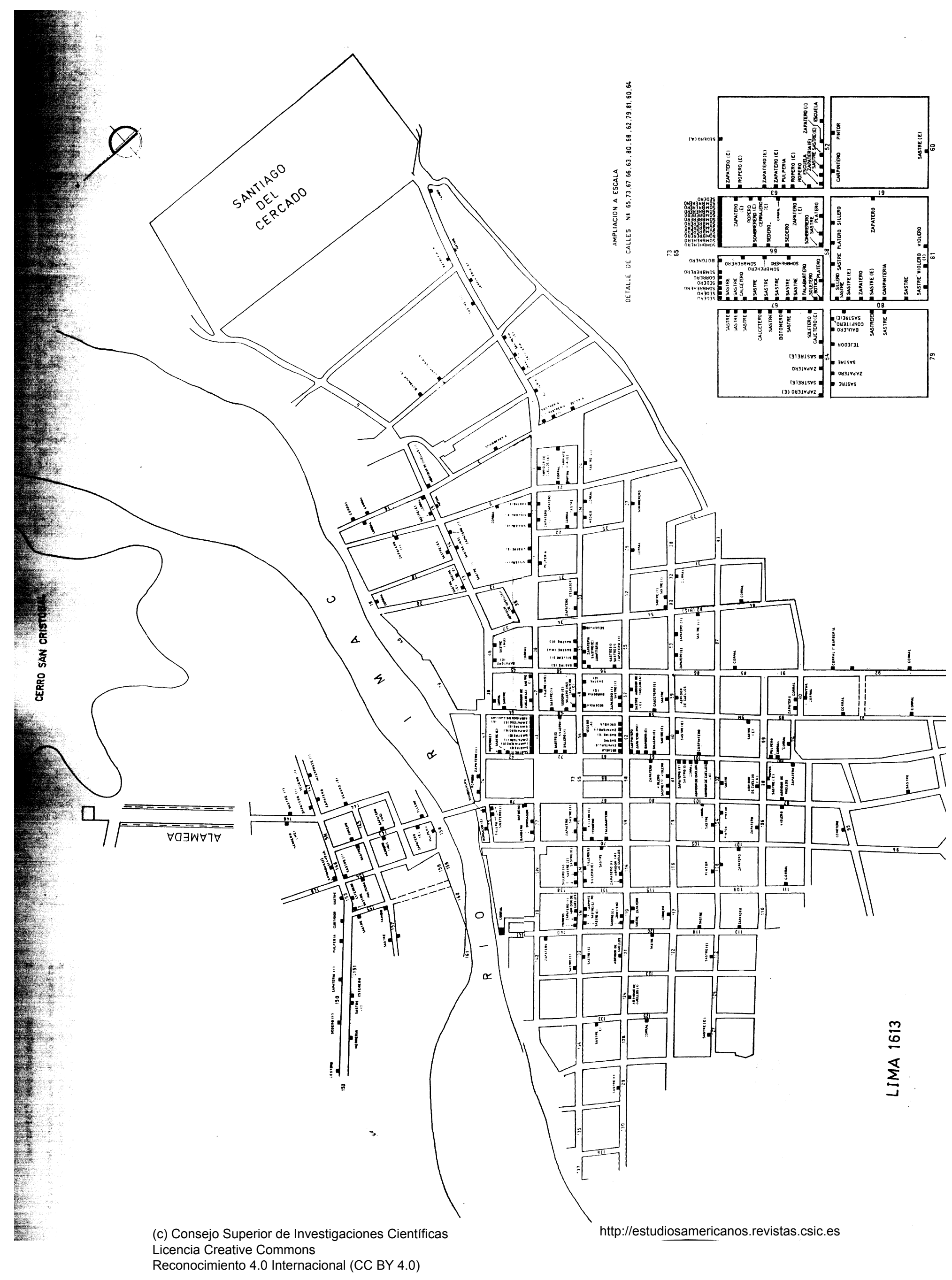


dad va creciendo y evolucionando, se pierde. A través del padrón de 1613 podemos hacer una aproximación a los tipos de vivienda existentes en la ciudad por estas fechas, teniendo en cuenta que la información de este documento se refiere fundamentalmente a indios.

Se mencionan como lugares de residencia los corrales en un número cercano a la treintena, los cuales hemos señalado en el plano adjunto. El corral, también denominado «callejón de cuartos», era una casa de vecinos, consistente en un «callejón» o pasillo a cielo descubierto perpendicular a la entrada, a cuyos lados se disponían las distintas viviendas o aposentos, que solían tener una o dos habitaciones y un patio utilizado como cocina y gallinero ${ }^{8}$.

En el Archivo Arzobispal de Lima hemos manejado un documento ${ }^{11}$ en el que Pedro Fernández de Valdés, alarife de la ciudad, realiza un informe en 1683 acerca de las reparaciones que necesita un corral propiedad de la cofradía de Nuestra Señora de la Candelaria. En él había catorce aposentos; el alarife va detallando las obras necesarias para su acondicionamiento $\mathrm{y}$ los materiales precisos: mangle, barro, esteras, caña brava; es decir, componentes pobres; únicamente la puerta de la calle se habrá de «recalzar con piedra y barro lo que está ahí comido». Como en casi toda la ciudad, el uso de la piedra se restringe ante lo costosa que resultaba al tener que traerla de Arica o Panamá, y mucho más en unas viviendas modestas, como son éstas.

Si observamos en el plano la ubicación de los «callejones de cuartos», encontramos que no se mencionan en San Lázaro, a pesar del carácter popular de este barrio. La mayoría se sitúan al este de una línea imaginaria que atravesase la Plaza Mayor de norte a sur. En general, salvo dos, se encuentran en zonas poco comerciales. Las excepciones están en las calles n. 103 y 63 . El primero se situaba frente al convento de

8 Harth Terré, Emilio y Márquez Abanto, Alberto: Historia de la casa urbana virreinal en Lima. Lima, 1962, pág. 55.

9 Archivo Arzobispal de Lima, Cofradías, 6. 
la Merced, en una zona un poco límite en lo que se refiere a actividaci comercial. Se encuentra a tres manzanas de la Plaza Mayor; las dos anteriores ( n. $^{\circ} 67$ y 80 ) estáín plagadas de tiendas, en ésta el número de las mismas desciende. El segundo se encontraba muy próximo a la Plaza, en la calle de los Roperos.

La mayor concentración de corrales se da entre las calles n. 15 y 16 , en una zona próxima al río, con siete en total, y en el área aledaña a la recoleta franciscana de Nuestra Señora de Guadalupe, el monasterio de la Encarnación y los Niños Huérfanos (n. ${ }^{\circ} 90$ a 93 ), donde hay seis. El resto aparecen diseminados sobre todo por la parte oriental de la ciudad.

Es curioso que uno de los corrales esté en la parte trasera de Santo Domingo (n. ${ }^{\circ} 141$ ). Años después, en el plano que de este edificio hace fray Juan Meléndez, figura un corral en una esquina del convento próxima al río.

Respecto al número de familias que vivían en cada una de estas viviendas, resulta difícil de precisar, pues sólo se censa a los indígenas. El número máximo es de nueve familias en el corral del Tercero (n. 15). En otros casos se menciona a una sola familia, lo cual es imposible, pues se supone que debe haber más gente, pero deben pertenecer a otras ctnias.

En relación a quiénes son los propietarios de estas viviendas comunitarias, también hay variedad de situaciones, sin faltar casos en los que no se da ningún dato en este sentido.

Algunos de estos «callejones de cuartos» son propiedad de mujeres. Así Francisca de Lorenzo, mulata, tiene el suyo en la calle n. ${ }^{\circ} 16$ y María de Sosa, morena, en la n. ${ }^{\circ}$ 92. De las restantes no se menciona raza; son Ana Maria, viuda de Diego López (n. ${ }^{\circ}$ 2), Catalina de Acuña (n. 90), Francisca Beltrán (n.0 93), María de Ocampo (n. $\left.{ }^{\circ} 100\right)$, Juana del Castillo (n. $\left.{ }^{\circ} 103\right)$ y Luisa de Ayala (n..$^{\circ} 125$ ).

Quizás esta abundancia de corrales en maı os femeninas podría ser una manera de subsistir a través de las rentas de los mismos de una manera digna, sin tener que realizar trabajos mal vistos en la época o depender de parientes. 
Hay cuatro corrales cuyos dueños trabajan en la administración. Uno de ellos pertenece a Francisco Hernández Crespo, oficial mayor de Gobierno ( . $^{\circ} 23$ ). Los tres restantes son de escribanos. Francisco de Velasco, escribano real, tiene el suyo situado en la calle n. ${ }^{\circ} 85$. Antonio Alcalá Ugarte, escribano de los naturales, lo tiene en la calle 94 y Alonso de Carrión, escribano de Cabildo, en la 111. También aparece una cofradía, la de Santa Catalina de Siena, como dueña de un corral. Existe otro denominado de La Merced, que acaso pudiera pertenecer a este convento; el que sin duda pertenece al de Santo Domingo es el mencionado anteriormente ( $n .^{\circ} 141$ ).

De los restantes sólo se mencionan los oficios de los propietarios en dos casos. Gregorio de Mújica es latonero y su corral es uno de los más concurridos, con ocho familias indias residiendo en él ( $\mathrm{n} .^{\circ}$ 90). El otro es de un barbero, Juan de Lemos $\left(n .^{\circ}\right.$ 92). Bromley nos facilita información sobre otros casos; así el de Tercero debe su nombre al :apellido de su dueño, un mecánico español ${ }^{10}$. Miguel Rodríguez, también propietario, ( . $^{\circ}$ 22) era almotacén o encargado de la limpieza de la ciudad en $1602^{11}$.

Un caso curioso es el de don Hernando Niño de Guzmán, también dueño de un corral ( $\left.\mathrm{n}^{\circ}{ }^{\circ} 36\right)$. Era arcediano, canónigo y chantre de la catedral ${ }^{12}$. Su propiedad estaba junto a su casa, de ahí su situación más céntrica que los de la mayoría. Casos como éste pueden ser un intento de mejorar la economía de la persona, a pesar de que por su posición debía ser buena.

Independientemente de los «callejones de cuartos» aparecen numerosos casos de arriendos y subarriendos de viviendas. Es frecuente que en una casa convivan varios grupos familiares. Nos encontramos con un fenómeno de tugurización que nada tiene que ver, apenas ochenta años después de fun-

10 Bromley, Juan y Barbagelata, José: Evolución urbana..., pág. 12.

11 Ibidem, pág. 15.

12 Ibidem, pág. 15. 
caada la ciudad, con los criterios iniciales de distribución de solares.

El caso de los subarriendos se agudiza en unas áreas concretas de la población. En la calle del Cercado (n ${ }^{\text {os }} 1$ a 3 ) contabilizamos 27 casas en las que se da esta circunstancia. Tres de ellas pertenecen a mulatos, tres a indios, una a una morena y el resto suponemos que a españoles. En algunas de estas viviendas llegan a residir un número considerable de familias, hasta siete en la de Alonso Ramírez Tarragona o cinco en la de Francisco de Elías.

Otra zona en la que también abundan, aunque en menor medida, es en las traseras del convento de San Francisco. Muy numerosos son en San Lázaro, sobre todo en Malambo ( n $^{\text {os }}$ 150 y 151). Aquí figuran 25 casas con subarriendo, con una cantidad considerable de inquilinos por vivienda (cinco en casa de Jerónimo de Ayala). Dentro del mismo iarrio también abundan en el Rastro (n. ${ }^{\circ} 156$ ), en las casas dentro de él habitan numerosos indios sobre todo en la llamada Ranchería del Rastro, donde se mencionan catorce.

En la zona centro de Lima residen indios, pero suelen ser dueños de talleres allí situados, que viven en el mismo lugar de trabajo, y también aprendices que se asojan con sus maestros; si bien, la mayoría de los que trabajan en este área residen en lugares periféricos de la ciudad, como los que estamos mencionando, o incluso en el Cercado, Magdalena o El Callao.

En esta parte central es donde reside la «aristocracia urbana» con preferencia; son descendientes de los primeros pobladores, encomenderos, miembros del Cabilds o altos cargos de la administración, personas todas ellas a las que se les supone una situación económica desahogada, pero que posiblemente en mayor o menor medida realizaban subarriendos en sus moradas. Es el caso de los Aliaga: en los bajos de su vivienda había una sillería $\left(\mathrm{n}^{\circ}{ }^{\mathrm{0}} 75\right)$. El arrendar la planta inferior de las casas como tiendas va a ser habitual, teniendo en algunos casos que intervenir el Cabildo, pues las ventanas del 
piso bajo se transformaban en puertas y la habitación se alquilaba como local para instalar en él un taller 0 un comercio.

Por el padrón deducimos que los indios económicamente mejor situados vivían y tenían sus posesiones sobre todo en dos zonas de la ciudad: calle del Cercado y San Lázaro.

En el primer enclave encontramos dos indios de los que se dice tienen tienda propia; son Juan de Herrera, sastre, y Francisco Huerta, zapatero. El primero tiene una esclava negra y el segundo tierras en Lati. Deducimos que deben ser además dueños de las casas que habitan.

Los restantes viven en San Lázaro. Son Miguel Huamán, sastre con casa y dos esclavas negras $\left(n^{\circ}{ }^{\circ} 146\right)$; Sebastián Francisco, zapatero, dueño de una casa y una esclava negra con un hijo mulato (n. ${ }^{\circ}$ 147); Martín Rodríguez, sastre, propietario de dos casas y tres esclavas ( $\mathrm{n}^{\circ}$ 148); Domingo Martín, sedero con casa y dos esclavos; Miguel Carua, con idénticas propiedades; éstos dos últimos residían en Malambo, como Gregorio Hernández, labrador y alcalde de los naturales, dueño de casa y tres esclavos. En esta misma calle residían Alcnso de Guadalupe, Colqueyana, Andrés Pérez y Juan Huamán «el Rico», todos ellos con vivienda propia, aunque en algurıos casos tenían parte de las mismas alquiladas a otras familias.

Entre los llamados indios de «China, Japón y las Indias de Portugal» no se mencionan propietarios; posiblemente su situación económica fuese en aquellos momentos peor que la de los indígenas. Muchos de ellos son esclavos o lo han sido y de algunos se dice que tienen «herrado» el rostro o bien el rostro y la barba. Respecto a los dueños de estos esclavos no se especifica; posiblemente fuesen españoles.

\section{Los OFICIOS EN LIMA}

Sobre la reconstrucción de la ciudad realizada por Juan Bromley y con ayuda del padrón hemos elaborádo el plano adjunto, en el que intentamos situar las tiendas y talleres men- 
cionados en el citado documento. En el mismo se incluye en algunos casos el enclave concreto de unas y otros dentro de la calle, pero en otras ocasiones sólo se nos indica que estaba en esa vía, mas no su situación exacta dentro de cilla. Por ello unas veces la ubicación es precisa y otras aproximada. A veces aparecen unas letras indicativas del grupo étnico al que pertenecía la persona que dirigía el taller (i: indio, me: mestizo, mu: mulato, e: español, a: asiático); sin embargo, en numerosas ocasiones el empadronador no indica este dato. Una vez más aclaramos que es posible que existiesen más obrajes no mencionados por no trabajar indios en ellos.

A la vista del plano podemos observar que el mayor número se encontraba en el lado sur de la Plaza Mayor y sus aledaños. En el Portal de Botoneros (n..$^{\circ}$ 65) predominan los de este oficio junto con sederos, talabarteros, botoneros y gorreros. Muy concurrido era el Callejón de Sombrereros ( $n .^{\circ}$ 66), donde junto a éstos trabajaban sederos; que también los había en unos cajones junto a la catedral.

En la calle de los Mercaderes ( $n .^{\circ}$ 67) ábundaban los sastres, doce en total. Debían ser sastrerías importantes por el número de operarios que trabajaban en ellas. Una era la de Andrés Núñez, proveedora del virrey, donde había ocho indios laborando. Además de sastres había en esta calle calceteros, soleteros, talabarteros y botoneros. La continuación de Mercaderes hacia la Merced ( $\left.\mathrm{n}{ }^{\circ} 80\right)$ era también prolija en tiendas, con predominio de sastres, aunque en menor medida, igual que la cuadra siguiente $\left(n .^{\circ} 103\right)$.

En la calle de los Roperos ( $\mathrm{n}^{\circ}$ 63) abundaban los ropavejeros, junto con zapateros. En Plateros de San Agustín $\left(n{ }^{\circ}\right.$ 68) trabajaban los de este oficio, aunque no exclusivamente.

Los plateros son los únicos que se sitúan en una sola calle, pues las ordenanzas del gremio solían disponer que estuviesen próximos para un mayor control de los metales que utilizaban. En el padrón se mencionan varios. Diego de Requena y Miguel Bonifaz, dos de los nombrados, aparecen unos 
años antes, en 1597, firmando como testigos en las constituciones de la cofradía de San Eloy y Nuestra Señora de la Miscricordia, creada por los plateros de Lima en el convento de San Agustín ${ }^{13}$. El primero es mencionado como tasador de las alhajas del convento de Santa Catalina en $1630^{14}$ y el segundo trabaja en la elaboración de una corona para la imagen titular de la Concepción y en varias piezas de la catedral de Lima ${ }^{15}$. Otro de los citados es Juan de Azúa, del que no hemos encontrado ninguna referencia. En su taller figura un aprendiz indio, Pedro Pumaguanca, lo cual es curioso pues era este un oficio de españoles, al menos legalmente.

En la calle que seguía a ésta (.$^{\circ}{ }^{69}$ ), conocida como Colchoneros, predominan sastres y zapateros. Los mismos abundan en otra de las vías próximas a la plaza: la que discurría por la parte lateral de las casas del Arzobispo (n. ${ }^{\circ} 43$ ).

A medida que nos alejamos de la plaza el número de talleres va disminuyendo y se va «difuminando» por toda la ciudad. De todas formas hay una mayor abundancia de ellos en la parte este de la misma.

Los oficios contaminantes o peligrosos se alejan del centro, tal es el caso de un cohetero ( . $^{\circ}$ 95). Pero donde más abundan este tipo de talleres es en San Lázaro; curtidores, herreros y olleros se sitúan en este barrio.

Parece que hay un predominio de españoles dirigiendo talleres, si bien no están excluidos los de otras razas. Nos parece curioso que los asiáticos tengan preferencia por dos oficios: soleteros y abridores de cuellos, muchos de ellos ejerciendo su profesión en lugares próximos a la Plaza Mayor ( . $^{\text {os }}$ 57, 114, $47,80)$.

En relación a la pregunta de si se sitúan los de un mismo oficio en una zona, tenemos que decir que esto se cumple en el caso de los plateros. Con otros trabajos hay a veces un

13 Torre Revello, José: El gremio de plateros en las Indias Occidentales. Buenos Aires, 1932, pág. XXIV.

14 Vargas Ugarte, Rubén: Ensayo de un diccionario de artifices. Burgos, 1968, pág. 330.

15 Ibidem, pág. 176. 
predominio en un área, pero no la exclusividad. Pueden ser un ejemplo los mencionados sombrereros, en el portal de su nombre, o los sastres en la calle Mercaderes.

Los pintores también parecen tener tendencia a situarse en una zona ( $n .^{\text {os }} 104$ y 108), aunque los hay por toda la ciudad. En el padrón se cita a varios individuos con esta profesión. Francisco Taviri, Juan Sánchez, Agustín de Sojo, Diego Sánchez y Martín Alonso de Mesa aparecen sin especificar raza. Tomás Manta, Rafael Hernández, Juan Martín, Sebastián Quisi Yupanqui y Pablo Mariano, este último residente en la Compañía, son indios, como los siguientes, si bien éstos son aprendices; se trata de Juan Aunquillampa, que está en el taller de Diego Sánchez, Cristóbal de Barrios, en el de Sojo, y Domingo Tomás, que aprende el oficio en la Compañía.

De los mencionados apenas hemos encontrado noticias. Agustín de Sojo colaboró en el convento de Santo Domingo ${ }^{18}$, Diego Sánchez realizó pinturas para San Agustín de Huánuco y para la Magdalena ${ }^{17}$. Vargas Ugarte menciona en su Diccionario de Artífices a Martín Alonso de Villavicencio pero como escultor, no sabemos si es el citado en el padrón como pintor ${ }^{18}$.

En relación con profesiones ligadas a las artes se menriona a Juan Martínez de Arrona, escultor y arquitecto, que residía en la calle de la Concepción ( . $^{\circ} 33$ ), en cuyo taller figura un aprendiz, Pedro Limaco.

Hay profesiones que no necesitan un obraje para ejercerlas y por tanto no figuran en el plano. Empezaremos comentando aquellos trabajos relacionados con el sector primario que, según Paul Charney, están entre la población indígena ${ }^{19}$. Existen numerosos pescadores, que suelen residir $i n$ unas zonas concretas: calle del Cercado, proximidades de la plaza de Santa Ana, espacio comprendido entre el monasterio de la Encarnación, los Huérfanos y Guadalupe $\left(n .^{\text {os }} 84,92,93\right)$ y en

16 Ibídem, pág. 350.

17 Ibídem, págs. 135-136.

18 Ibídem, pág. 277.

19 Charney, Paul J.: El indio urbano..., pág. 28. 
San Lázaro. En este último lugar encontramos pastores, lógico teniendo en cuenta que en el mismo se encontraban las carnicerías de la ciudad.

Relacionados con la agricultura el censo cita a labradores y chacareros. Los primeros son minoritarios; se menciona a uno en la calle del Cercado, del que se dice tenía tierras propias, otro vive en un corral en la calle del Molino Que-brado ( . $^{\circ}$ 9). Los restantes residen en Malambo; son Juan Guamán «el Rico» y Andrés Pérez.

San Lázaro es lugar de residencia de numetosos chacareros, así como las calles a espaldas del convento de San Francisco y las inmediaciones del convento de la Concepción. Abundan también en zonas periféricas de la ciudad por el sur y el oeste $\left(\mathrm{n}{ }^{\text {os }} 95,100,112,129\right)$. Posiblemente se deba a que si, como dicen los cronistas, Lima estaba rodeada de huertas, las personas encargadas de cuidarlas viviesen en lugares próximos. Lizárraga nos dice al respecto «...desde fuera no parece ciudad, sino un bosque por las muchas huertas que la cercan» ${ }^{20}$.

Los sectores secundario y terciario ocupan a buena parte de la mano de obra indígena; prácticamente de ningún oficio están excluidos; aparte de los mencionados ya, hay albañiles, ladrilleros, estereros..., no faltan algunos especialmente llamativos, como un chasquero, que por lógica reside en la casa del Correo Mayor, Diego de Carvajal; o un intérprete de la Real Audiencia, morador en San Lázaro.

Una profesión tremendamente extendida es la de sirviente, tanto entre hombres como entre mujeres. Entre ellos no faltan casos de subempleo, pues dicen tener un oficio (sastre, zapatero, chacarero...), sin embargo se ganan la vida como criados. Como tales aparecen indios de Chile, de los que se especifica en ocasiones que son esclavos como consecuencia de las guerras que se mantienen en ese territorio. El servicio

20 Lizárraga, F. Reginaldo: Descripción y población de las Indias. Lima, 1908, pág. 53. 
doméstico es también trabajo desempeñado por muchos de los asiáticos.

Mejor vida debía llevar los jóvenes indios aue están en Lima estudiando. Hay dos alumnos en la escuela que Juan de Mendoza, español, tiene junto al hospital de San Lázaro. Varios más aprenden en las escuelas de Antonio Rodríguez de Vitoria y Marcos Picón ( . $^{\circ}$ 62). Un caso curioso es el del pequeño Antonio de Pariona, cacique de diez años de edad, que reside en la casa de Francisco de Nájera y Arauz de Toledo $\left(\mathrm{n}^{\circ}\right.$ 143), del que se dice que lleva hábito de penitente del Santo Oficio, para que éste le enseñe a leer y rezar.

Tampoco faltan quienes ejercen oficios relacionados con la iglesia: son los sacristanes, que suelen residir en las proximidades de las parroquias donde trabajan. Esto nos lleva a un grupo tratado aparte en el padrón; se refiere a los que trabajan en conventos y edificios religiosos. Sólo se enumeran varones, por ello en los monasterios femeninos aludidos (San José de las Descalzas, la Trinidad y la Encarnación) únicamente se cita en cada uno de ellos el sacristán, aunque en los mismos debían residir numerosas indias al sejvicio de las monjas.

En la mayoría de los conventos masculinos los indios aparecen como sirvientes y alguno desempeñando el ya citado cometido de sacristán o como cocineros. Lo mismo sucede en los colegios que las distintas órdenes religiosas tenían en $\mathrm{Li}$ ma. La excepción está en los edificios de los jesuitas; en ellos figuran criados pero pertenecientes a los colegiales que allí estudiaban, los restantes desempeñan oficios varios: hortelanos, sastres, pintores. Curioso es el caso de Santo Domingo donde reside un pergaminero, Juan Sulca, y dos indios más de los que se dice que acuden a que les den de comer. ¿Vivirán de la «sopa boba» conventual?

Otro grupo trabaja en los hospitales; la mayor parte lo hace en las enfermerías, no faltando sacristanes y hortelanos. Hay un caso peculiar, el de Francisco Alonso, cuya misión era ir recogiendo indios enfermos para llevarlos a Santa Ana. 
Numerosa población femenina trabaja; la mayoría lo hace como sirvientas dispersas por toda la ciudad. Una minoría son costureras y bordadoras, abundando las llamadas «gateras», es decir, las que venden en lugares públicos, fues según el padre Bernabé Cobo, «gato» es la transcripción española de una palabra quéchua que designa el mercado. Suelen vender maíz, frutas y en algunos casos comidas preparadas por ellas mismas, o bien chicha; estas últimas reciben el nombre de chicheras. Muchas residen en la zona de la parroquia de Santa Ana, en San Lázaro y en los alrededores de los Niños Huérfanos. Otro grupo de mujeres se debían ganar la vida arrendando parte de sus viviendas, situación extensiva a españolas y a las restantes etnias que convivían en Lima.

A la vista de lo hasta aquí expuesto podemos deducir varias conclusiones. En primer lugar el crecimiento de la ciudad ha deformado el trazado primitivo de la misma, sobre todo en las zonas este y sur, donde la irregularidad de calles, plazas y manzanas es notoria. Asimismo, la división original de estas últimas en cuatro solares se ha perdido casi por completo, apareciendo por toda la población el subarriendo y la tugurización. Son numerosos los vecinos, algunos de ellos pertenecientes a la «aristocracia urbana», que alquilan parte de sus viviendas a otras familias, o bien habitaciones de la planta baja como talleres o tiendas, dando lugar a un proceso de convivencia interracial. Asinismo abundan los corrales de vecinos o "callejones de cuartos». La población india reside en toda Lima, aunque parece ser que en mayor medida en el sur de la ciudad, alrededores de Santa Ana y San Lázaro. Es precisamente en los lugares mencionados al final cionde vivían los indios que gozaban de una mejor posición económica.

La zona comercial de la ciudad es sobre todo la Plaza Mayor y sus inmediaciones, si bien tiendas existen por toda la ciudad, sobre todo zapaterías y sastrerías. A esta zona céntrica acuden a trabajar personas que residen a veces en núcleos poblacionales fuera de Lima, como El Callao o Magdalena. Los talleres de profesiones que encierran un peligro po- 
tencial o bien son molestos por su contaminación se sitúan en zonas periféricas o en San Lázaro.

Salvo los plateros, que residen en una sola calle, Plateros de San Agustín, en las restantes profesiones no se da esta circunstancia, aunque en algunos casos hay una cierta tendencia a concentrarse en una misma área.

Al frente de los talleres encontramos, además de españoles, que son mayoría, personas de otras razas. No parece que hubiera profesiones de las que estuviera apartada la población indígena, ya que en el padrón figuran con los oficios más variados, si bien hay un predominio de sirvientes. Numerosas mujeres se ganan la vida arrendando parte de sus viviendas.

De lo dicho hasta ahora podemos sacar como conclusión final que la convivencia entre los distintos grupos étnicos, tanto en viviendas como en trabajos, era una realidad en la $\mathrm{Li}$ ma de 1613.

\section{Marí́ Antonia Durán Montero}

